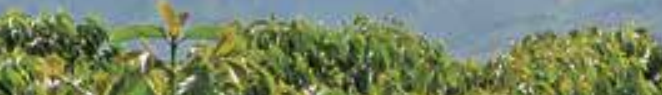
S.

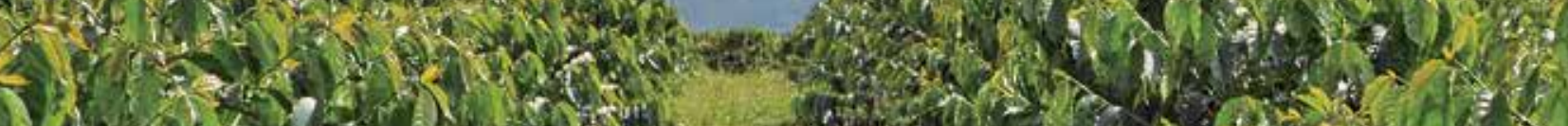

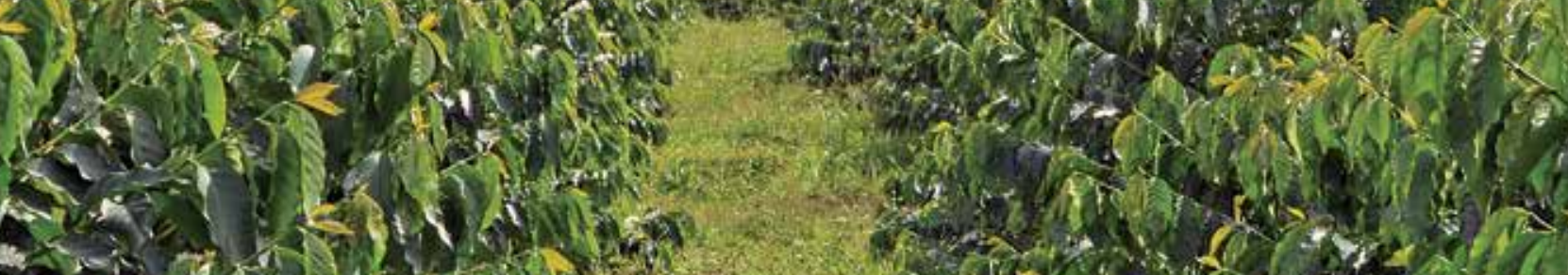
1.

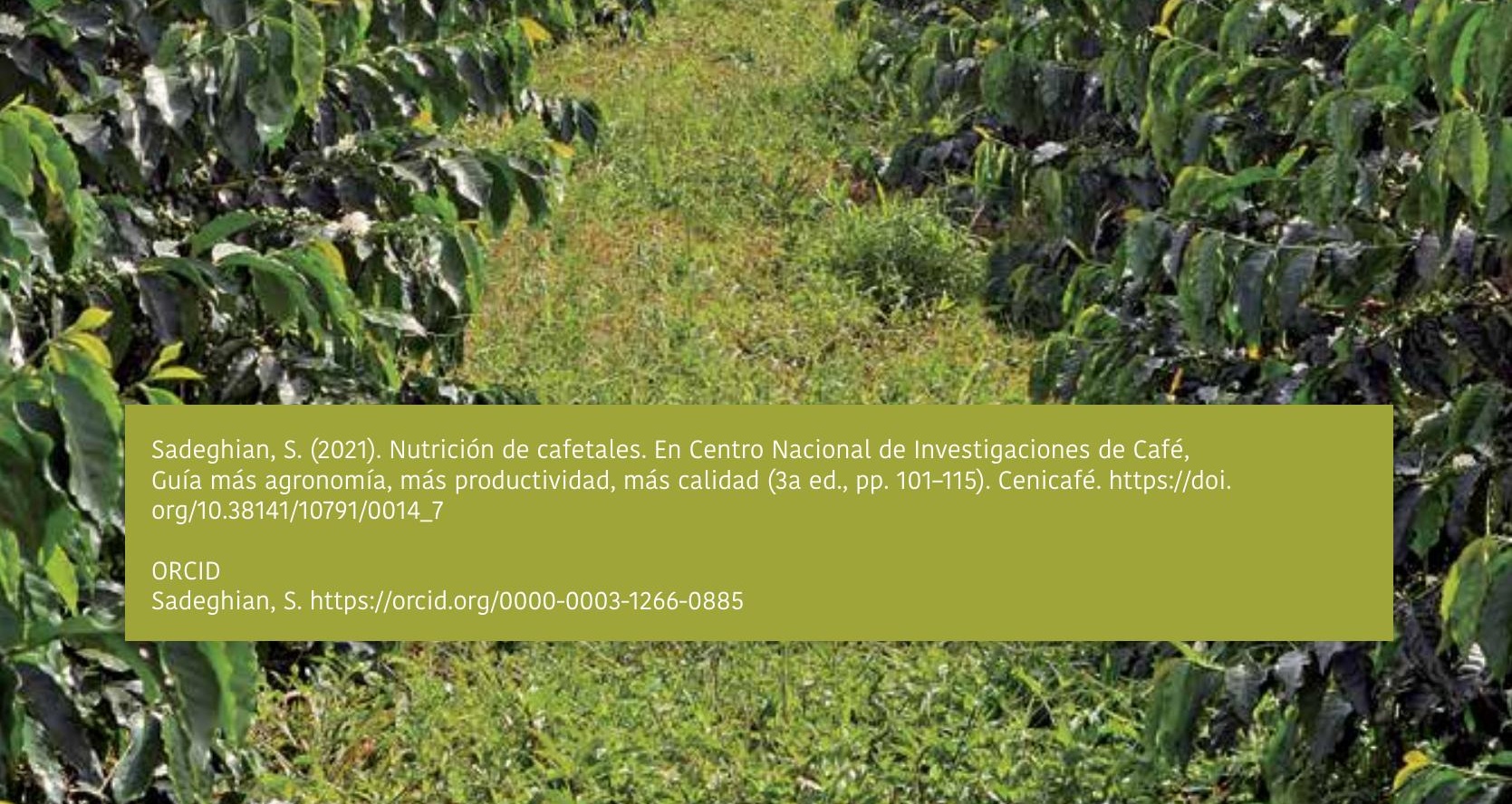




\section{NUTRICIÓN DE CAFETALES}

Siavosh Sadeghian Khalajabadi *

La productividad de los cafetales depende en gran medida de una adecuada nutrición.

Cuando las raíces de las plantas encuentran condiciones óptimas para

su crecimiento en el suelo y absorben en cantidades suficientes los

elementos que necesitan para realizar sus funciones, se alimentan adecuadamente y producen de manera sostenible cosechas abundantes y de buena calidad.

\section{Requerimientos nutricionales}

Los nutrientes de mayor demanda por las plantas son el carbono, hidrógeno y oxígeno; estos provienen del agua y de la atmósfera, y representan cerca del $95 \%$ del peso de la planta. El $5 \%$ restante se encuentra en el suelo $y$, por ello, son llamados minerales. El nitrógeno, fósforo, potasio, calcio, magnesio y azufre son los nutrientes minerales con mayor demanda, razón por la cual reciben el nombre de macronutrientes; otros como el hierro, manganeso, cobre, cinc, boro, cloro, molibdeno y níquel, por su baja demanda son llamados micronutrientes.

En café, los dos macronutrientes más absorbidos en todas las etapas del cultivo son el nitrógeno y el potasio; en un segundo plano se ubican el calcio, el fósforo, el magnesio y el azufre. Los requerimientos nutricionales de café aumentan con la edad, es así como durante la etapa de almácigo la planta crece lentamente y absorbe bajas cantidades de nutrientes, algo similar ocurre durante la etapa de levante; al iniciar la fase reproductiva la planta aumenta su velocidad de crecimiento y con ello se incrementa la demanda de nutrientes. 
Para obtener altas producciones es necesario que las plantas formen primero suficientes raíces, tallos, ramas y hojas; órganos que también demandan nutrientes, y sin los cuales sería imposible lograr este propósito.

\section{Fertilidad del suelo}

El suelo constituye el principal reservorio de los elementos minerales requeridos; sin embargo, la mayoría de las veces sus contenidos no son del todo suficientes, de allí la importancia de realizar acciones que permitan incrementar y mantener la fertilidad del suelo, mediante la aplicación de

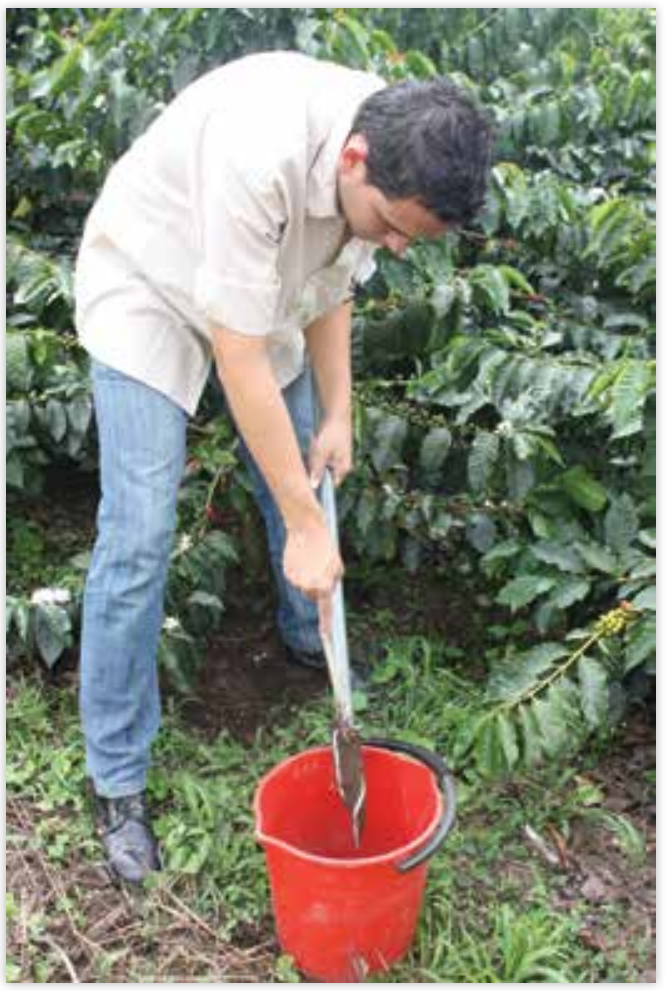

abonos y enmiendas. Cuando no se llevan a cabo prácticas adecuadas de fertilización la producción se reduce en más de $40 \%$ y en ocasiones hasta $80 \%$.

\section{Análisis de suelo}

Para conocer la fertilidad del suelo $y$ definir planes adecuados de nutrición es indispensable disponer de los resultados del análisis de suelo, herramienta que ayuda a reducir los riesgos económicos y ambientales. Para que el análisis de suelo tenga validez las muestras deben tomarse de manera adecuada y representativa de todo el lote, contar con un laboratorio confiable, interpretar los resultados correctamente y seguir las 
recomendaciones específicas para cada caso. El análisis de suelo también identifica el grado de la acidez y ayuda a definir las dosis y fuentes de enmiendas (cales) para la corrección del problema.

\section{Fertilización en la etapa de almácigo}

Contar con un almácigo vigoroso es el primer paso para el establecimiento exitoso de cafetales productivos y su permanencia en el campo; de allí la necesidad de llevar a cabo labores que contribuyan en su obtención, entre las cuales la nutrición ocupa un lugar importante. Para esta etapa resulta beneficiosa la mezcla de suelo y abonos orgánicos bien descompuestos (principalmente pulpa de café, lombrinaza, gallinaza y pollinaza), así como la adición de fósforo en forma de DAP y el encalamiento en suelos ácidos. La aplicación de fertilizantes vía foliar no ha tenido efectos en el crecimiento de las plantas.

\section{Fertilización en la etapa de levante}

Antes de sembrar el colino en el campo deben realizarse las adecuaciones necesarias para mejorar las características físicas, químicas y biológicas del suelo mediante la aplicación de enmiendas, como abonos orgánicos y cales. Durante esta etapa, el nitrógeno es el elemento de mayor requerimiento $y$, por lo tanto, debe incluirse en todas las aplicaciones, pues de lo contrario la producción de la primera cosecha puede reducirse en $40 \%$.

El suministro de fósforo, potasio y magnesio puede quedar sujeto a los resultados de los análisis de suelos.

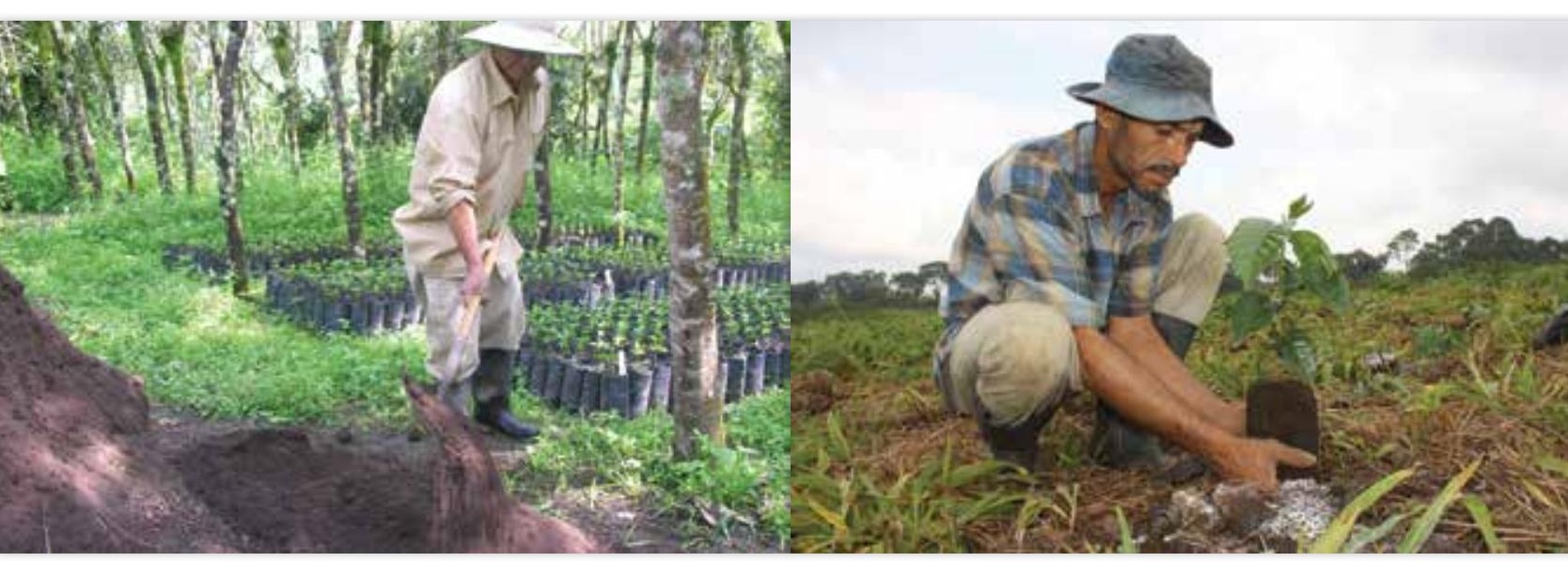


En un plan general de fertilización (sin análisis de suelo), pueden suministrarse las siguientes cantidades de nutrientes durante los primeros 18 meses después de la siembra: nitrógeno $60 \mathrm{~g} /$ planta, fósforo- $\mathrm{P}_{2} \mathrm{O}_{5} 15 \mathrm{~g} /$ planta, potasio- $\mathrm{K}_{2} \mathrm{O} 15 \mathrm{~g} /$ planta, magnesio-MgO $5 \mathrm{~g} /$ planta. En el caso de contar con un análisis de suelo, será posible reducir las anteriores dosis, las cuales pueden distribuirse en tres o cuatro aplicaciones al año, de acuerdo a la cantidad y distribución de la lluvia.

\section{Fertilización en la etapa de producción}

El nitrógeno se considera el nutriente más limitante de la producción, pues cuando se excluye de los planes de fertilización, el rendimiento puede reducirse hasta en $80 \%$. El potasio ocupa el segundo lugar $y$ en suelos deficientes pueden presentarse reducciones de la producción cercanas al $30 \%$. La respuesta al suministro de fósforo es ocasional y de baja magnitud, con una reducción en el rendimiento cuando los niveles de éste en el suelo son bajos. Es común observar deficiencias de magnesio en las hojas de las ramas productivas a medida que avanza el desarrollo de los frutos, pese a ello, las cantidades requeridas de este elemento no son altas. Rara vez se detectan síntomas

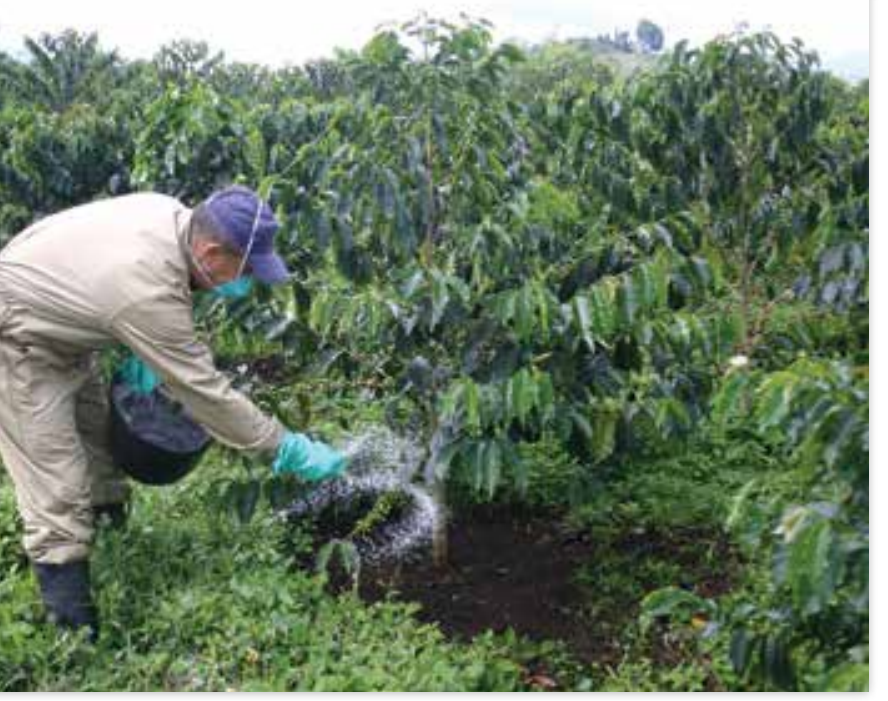
de la deficiencia de azufre en las diferentes regiones cafeteras del país, y en cuanto a la respuesta a la fertilización se refiere, las cantidades requeridas se asemejan a las del fósforo $y$ magnesio. Dada la poca ocurrencia de deficiencias de elementos menores en la mayoría de las regiones cafeteras del país, actualmente no se sugiere incluirlos de manera general en los planes de fertilización. 
En general, mediante el suministro de las siguientes cantidades de nutrientes logran cubrirse las necesidades de los cafetales tecnificados con altas densidades de siembra y bajo nivel de sombra: $300 \mathrm{~kg} / \mathrm{ha} /$ año de nitrógeno- $\mathrm{N}, 260 \mathrm{~kg} / \mathrm{ha} / \mathrm{año}$ de potasio- $\mathrm{K}_{2} \mathrm{O}$ y $50 \mathrm{~kg} / \mathrm{ha} / \mathrm{año}$ de fósforo- $\mathrm{P}_{2} \mathrm{O}_{5}, 50 \mathrm{~kg} / \mathrm{ha} /$ año de magnesio-MgO y $50 \mathrm{~kg} / \mathrm{ha} / \mathrm{año}$ de azufre-S. Estas cantidades pueden ajustarse con base en el análisis de suelo, la información acerca de la densidad de plantas por hectárea y el nivel de sombra.

\section{Puede distribuirse la dosis total normalmente en dos aplicaciones al} año, pero excepcionalmente en tres, teniendo en cuenta la cantidad y las propiedades del fertilizante, así como el régimen de la lluvia.

\section{Epocas de aplicación}

Todo plan de fertilización, bien sea en el levante o la producción, está sujeto a la lluvia, dado que el agua además de disolver los fertilizantes, es el insumo indispensable para la absorción de los nutrientes desde la solución del suelo. Esta condición prevalece por encima de las épocas de mayor demanda nutricional por la planta o el fruto. Por lo anterior, se recomienda realizar la fertilización al comenzar los períodos Iluviosos; en contraste, el encalamiento puede realizarse en verano.

\section{Fuentes de fertilizantes y enmiendas}

En el mercado nacional existe una amplia gama de fuentes. Al momento de escoger, los factores más determinantes son: los requerimientos del cultivo, la calidad del producto (contenido y aporte nutricional, solubilidad, granulometría, efecto sobre el suelo, concentración de elementos tóxicos y consistencia del gránulo, entre otros) y el costo por hectárea. Se ha demostrado que los fertilizantes obtenidos mediante mezcla física generan resultados similares en producción y calidad del grano que los complejos granulados. 
Para la mayoría de las regiones del país, mediante el suministro de las siguientes cantidades de nutrientes logran cubrirse las necesidades de los cafetales tecnificados con altas densidades de siembra y bajo nivel de sombra: $300 \mathrm{~kg} / \mathrm{ha} /$ año de nitrógeno-N,

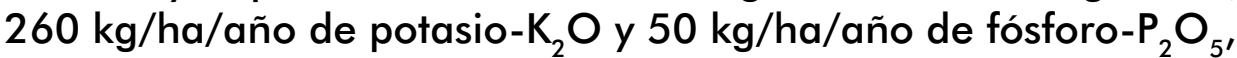
$40 \mathrm{~kg} / \mathrm{ha} /$ año de magnesio-MgO y $50 \mathrm{~kg} / \mathrm{ha} / \mathrm{año}$ de azufre-S. En concordancia con las dosis recomendadas, una relación adecuada entre nitrógeno, fósforo, potasio, magnesio y azufre sería de $6,0: 1,0: 5,2: 0,8: 1,0$.

Las cantidades mencionadas pueden suministrarse mediante diferentes fertilizantes. Una opción sería a partir de la mezcla de $630 \mathrm{~kg} / \mathrm{ha} / \mathrm{año}$ de urea (46-0-0), $100 \mathrm{~kg} / \mathrm{ha} / \mathrm{año}$ de fosfato mono amónico-MAP (10-50-0), $352 \mathrm{~kg} / \mathrm{ha} / \mathrm{año}$ de cloruro de potasio-KCl (0-0-60) y $222 \mathrm{~kg} / \mathrm{ha} /$ año de sulfato doble de magnesio y potasio [0-0-22-18(MgO)-22(S)]. La cantidad total de la anterior mezcla, es decir, $1.304 \mathrm{~kg}$, estaría conformada en el $22 \%$ por nitrógeno-N, $4 \%$ por fósforo- $\mathrm{P}_{2} \mathrm{O}_{5}, 20 \%$ por potasio- $\mathrm{K}_{2} \mathrm{O}, 3 \%$ por magnesio$\mathrm{MgO}$ y $4 \%$ de azufre-S; por lo tanto, el grado que se genera es aproximadamente 22-4-20-3(MgO)-4(S).

Cuando no se requiera de magnesio o azufre, se podrán mezclar 630 $\mathrm{kg} / \mathrm{ha} / \mathrm{año}$ de urea, $100 \mathrm{~kg} / \mathrm{ha} / \mathrm{año}$ de MAP (10-50-0) y $433 \mathrm{~kg} / \mathrm{ha} /$ año de $\mathrm{KCl}$ (0-0-60); en este caso, el grado que se obtiene corresponde a 26-4-22 y la cantidad total a $1.164 \mathrm{~kg} / \mathrm{ha} / \mathrm{año}$.

Es conveniente recalcar que las dosis sugeridas de los nutrientes pueden ajustarse con base en el análisis de suelo, la información acerca de la densidad de plantas por hectárea y el nivel de sombra. 
Fertilizante con nitrógeno, fósforo, potasio y magnesio.

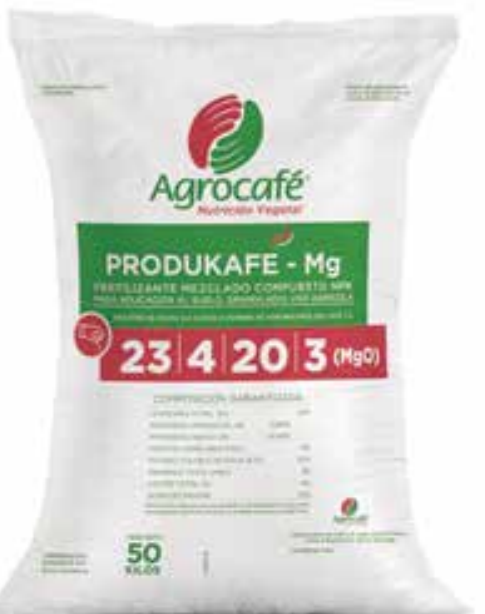

Fertilizante con nitrógeno, fósforo y potasio.

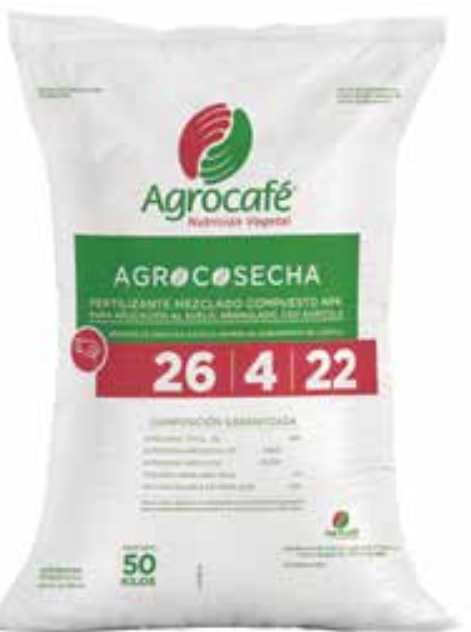




\section{Análisis de suelos: Vutra bien sus teffetales}

\section{Obtenga cosechas abundantes y de buena calidad}

IFs la única herramienta que permite tomar la decisión del

uso de enmiendas y correctivos en cafetales.

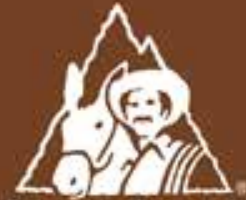

Pederación Nacional de Cafeteros de Colombia

\section{correctivos en cafetales.}

Es esencial para:

El diagnóstico de la
disponibilidad de nutrientes en el
suelo.

Estimar la cantidad de fertilizantes y enmiendas requeridos.

Evaluar el estado de la fertilidad del suelo en una finca o region.

\section{Ventajas}

En suelos poco fértiles permite recomendar altas cantidades de nutrientes, pero solo de aquellos que son requeridos porla planta.
En suelos muy fértiles las cantidades de fertilizantes sugeridas son menores respecto a la fertilización sin análisis de suelos.

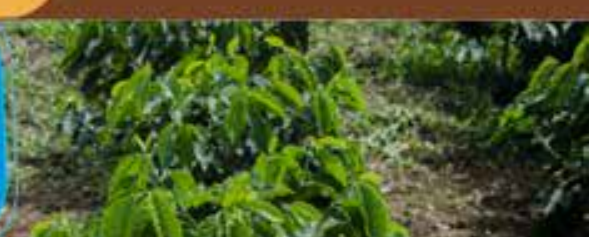




\section{Análisis de sudas}

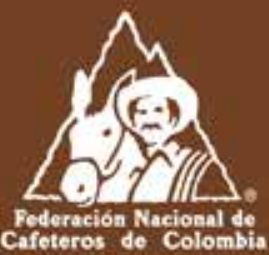

\section{Conozca la fertilidad de los suelos de su finca}

\section{icómo tomar las muestras de suelo?}

\section{Q}

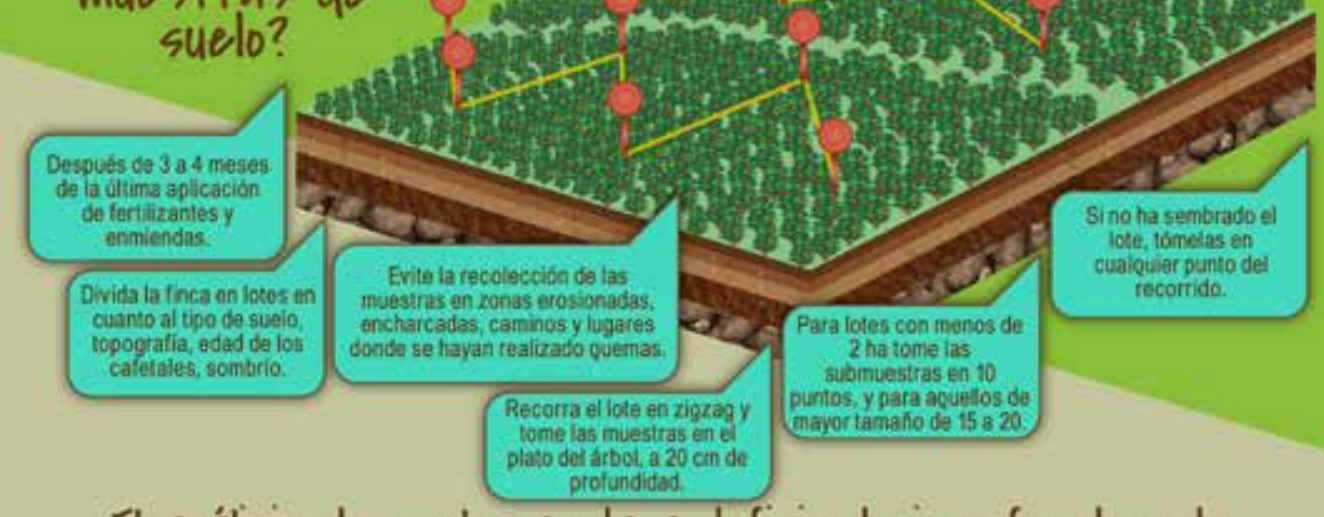

El análisis de suelos ayuda a definir dosis y fuenters de fertilizantes y enmiendas para sus cafetales.
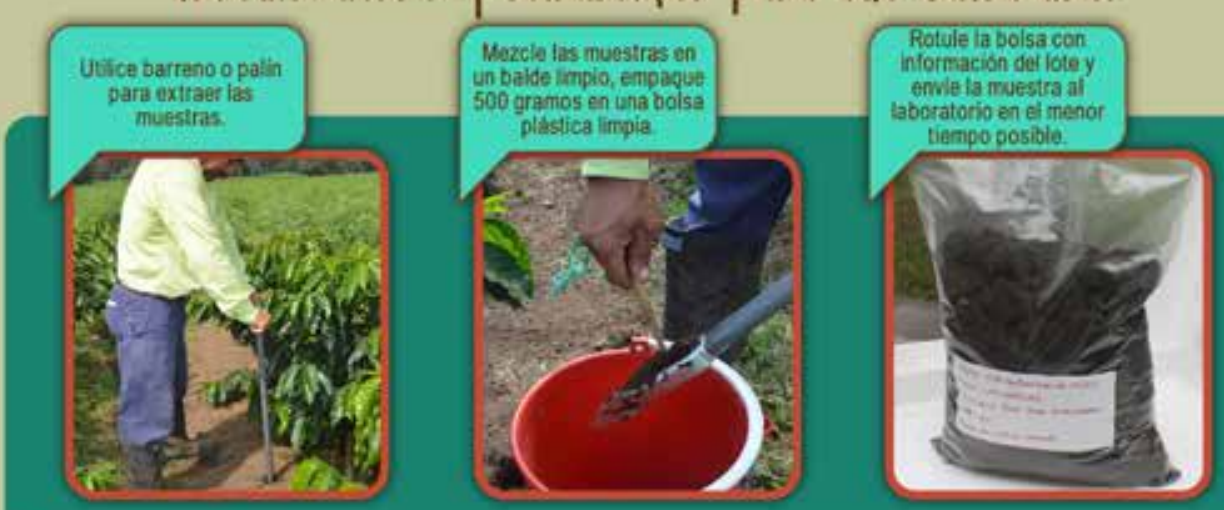

\section{caficultor:}

Consulte con su Extensionista para la interpretación de los resultados y las recomendaciones. Los cafetales bien nutridos producen cosechas abundantes y de buena calidad. Realice un nuevo muestreo después de dos años

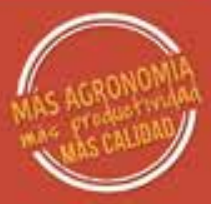




\section{Ritrúgend (N)}

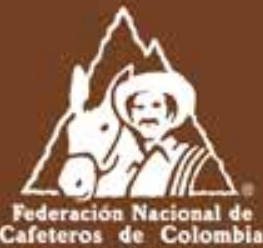

\section{Flemento esencial para el crecimiento y la producción de café}

En levante

Obtener plantas vigorosas

Fertilice con

nitrógeno

Promover la formación de raices, hojas, ramas y frutos

\section{para: \\ Lograr buenas producciones}

¿Guánto aplicar?

Entre 50 y 80 gramins por planta, distribuidos en 5 a 6 aplicaciones durante los 18 meses después de la siembra

La materia orgánica del suelo es fuente de nitrógeno, pero es insuficiente. Por esta razón incluya siempre este nutriente en el plan de fertilización

\section{Caficultor:}

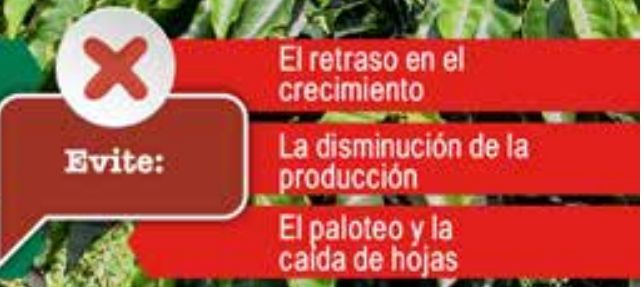

\section{En producción \\ Hasta $300 \mathrm{~kg} / \mathrm{ha}$ al afí, fraccionados en 2 aplicaciones}

El nítrógeno es esencial para el café, al incluirlo siempre en los planes de fertilización, no comprometerá el crecimiento ni la producción de su cultivo consulte con su Extensionista

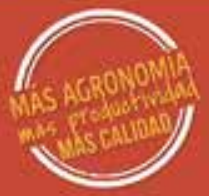




\section{Fúsforo (P)}

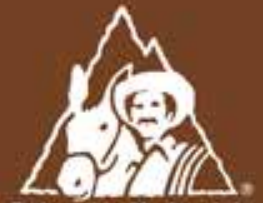

\section{Garantice el crecimiento}

del café desde la raíz

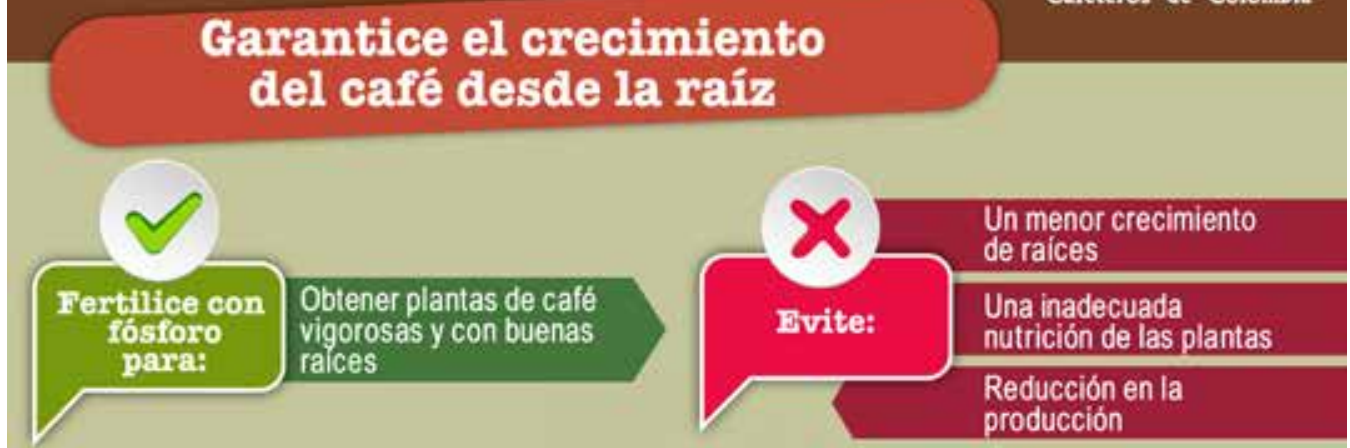

¿Guánto aplicar?

En levante

Hasta 15 gramos por planta, distribuidos en 3 aplicaciones durante los 18 meses después de la siembra

\section{En producción}

Hasta B0 kilogramos por hertárea y año, según el análisis de suelos

Es indispensable principalmente durante las etapas de almácigo y establecimiento

\section{caficultor:}

Una adecuada fertilización con fósforo permite al café un mayor aprovechamiento del agua, los nutrientes y adaptación a condiciones ambientales desfavorables para el cultivo consulte con su Extensionista

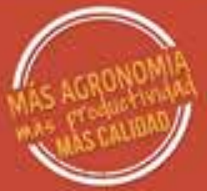




\section{Potasio (K)}

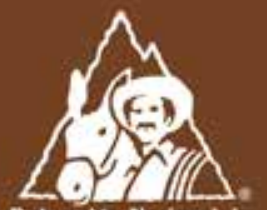

Federación Nacional de

Nutriente clave en la producción Cafeteros de Colombia y calidad del café

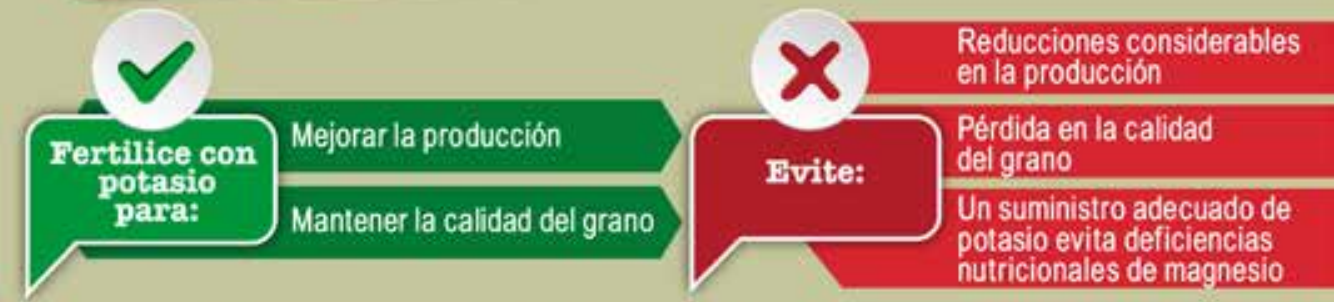

\section{¿Guánto aplicar?}

En levante

Para prevenir deficiencias, lasta 15 gramis por planta, distribuidos en 2 aplicaciones a partir de los 6010

meses después de la siembra, según el caso

Todos los órganos de la planta requieren el potasio para su crecimiento. LoS frutos en especial, presentan altas concentraciones de este

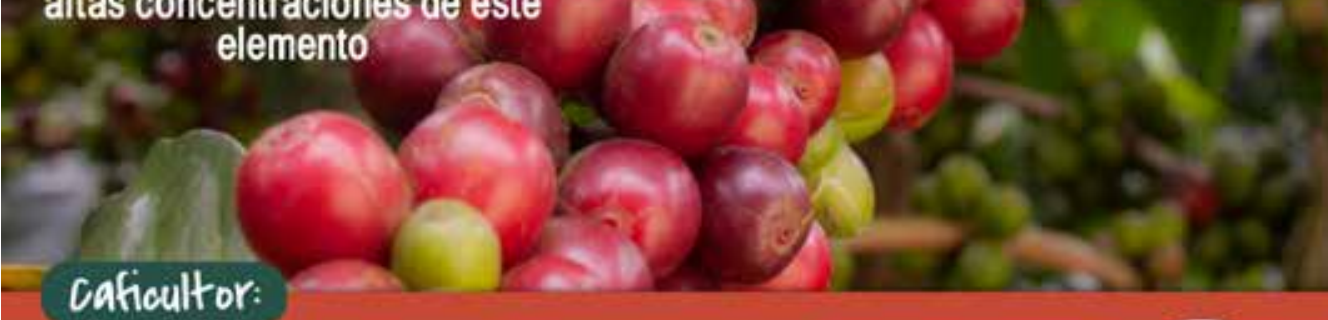

Caficultor:

Para mantener reservas suficientes de potasio en el suelo y lograr buenas cosechas, incluya este elemento en su plan de fertilización Consulte con su Extensionista

En producción

En la mayoria de los casos, son suficientes 280 kilogrames por hectérea y año 


\section{Mannfesio (Mg)}

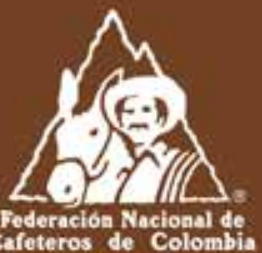

\section{Mantenga plantas verdes, vigorosas y productivas}

El suministro de magnesio ayuda a mantener niveles adecuados del nutriente en

el suelo y previene sus deficiencias.
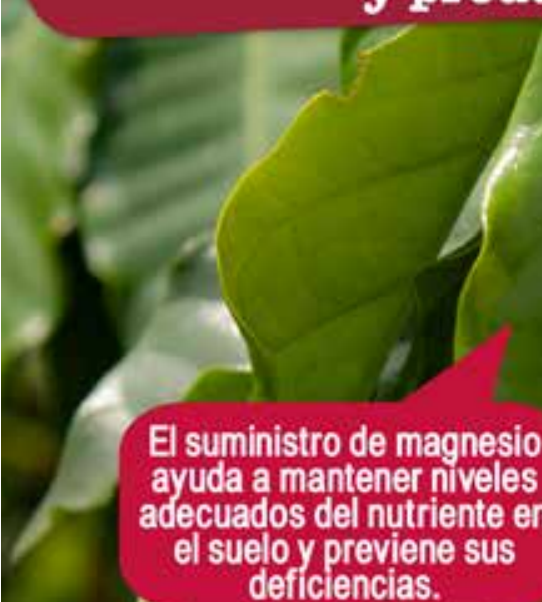

El magnesio hace parte de la clorofila y ayuda a Que las plantas permanezcan siempre verdes, vigorosas y productivas.

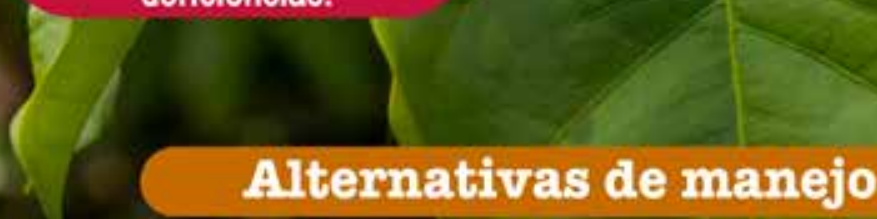

Caliza dolomítica para corregir la acidez del suelo y suministrar magnesio.

$\checkmark$ Fertilizantes simples o compuestos que contengan magnesio y recomendados para la caficultura en Colombia:

\section{En levanto \\ Hasta 5 gramns por planta de magnesio, en dos aplicaciones, a partir de los 10 meses después de la siembra}

\section{En producción}

40 kilonramos por hectírea al alio de magnesio. Esta cantidad se puede ajustar

de acuerdo con el análisis de suelos

\section{caficultor:}

Realice el análisis de suelos y siga las recomendaciones para evitar las deficiencias de magnesio en el suelo y su cultivo

$$
\text { Consulte con su Extensionista }
$$

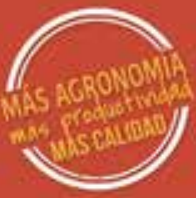




\section{Fertilice oportunamente}

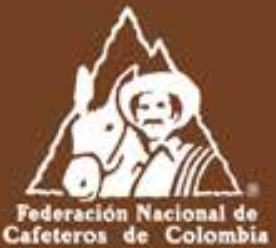

\section{Asi garantiza el crecimiento y la producción del café}

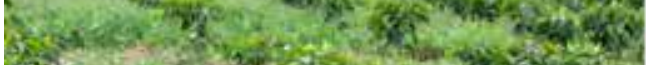

El exito de la fertilización depende de la cantidad y las épocas adecuadas de aplicación.

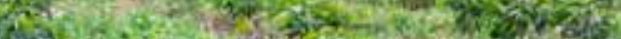

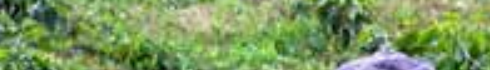

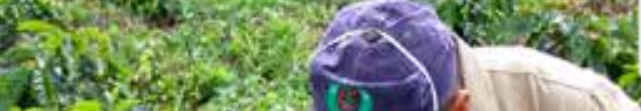

Los nutrientes Que se aplican en la fertilización pueden permanecer en el suelo por varios meses.

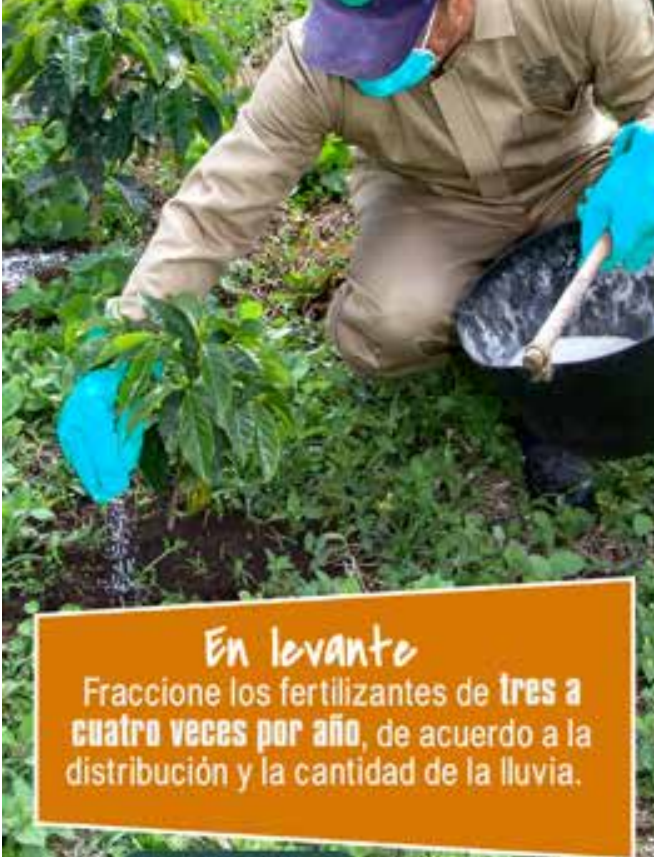

caficultor:

Una fertilización adecuada y oportuna da lugar a plantas vigorosas y previene las deficiencias nutricionales en el cultivo.

Consulte con su Extensionista

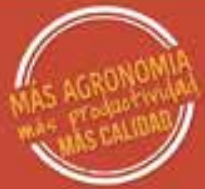




\section{Fertilizantes para teafó}
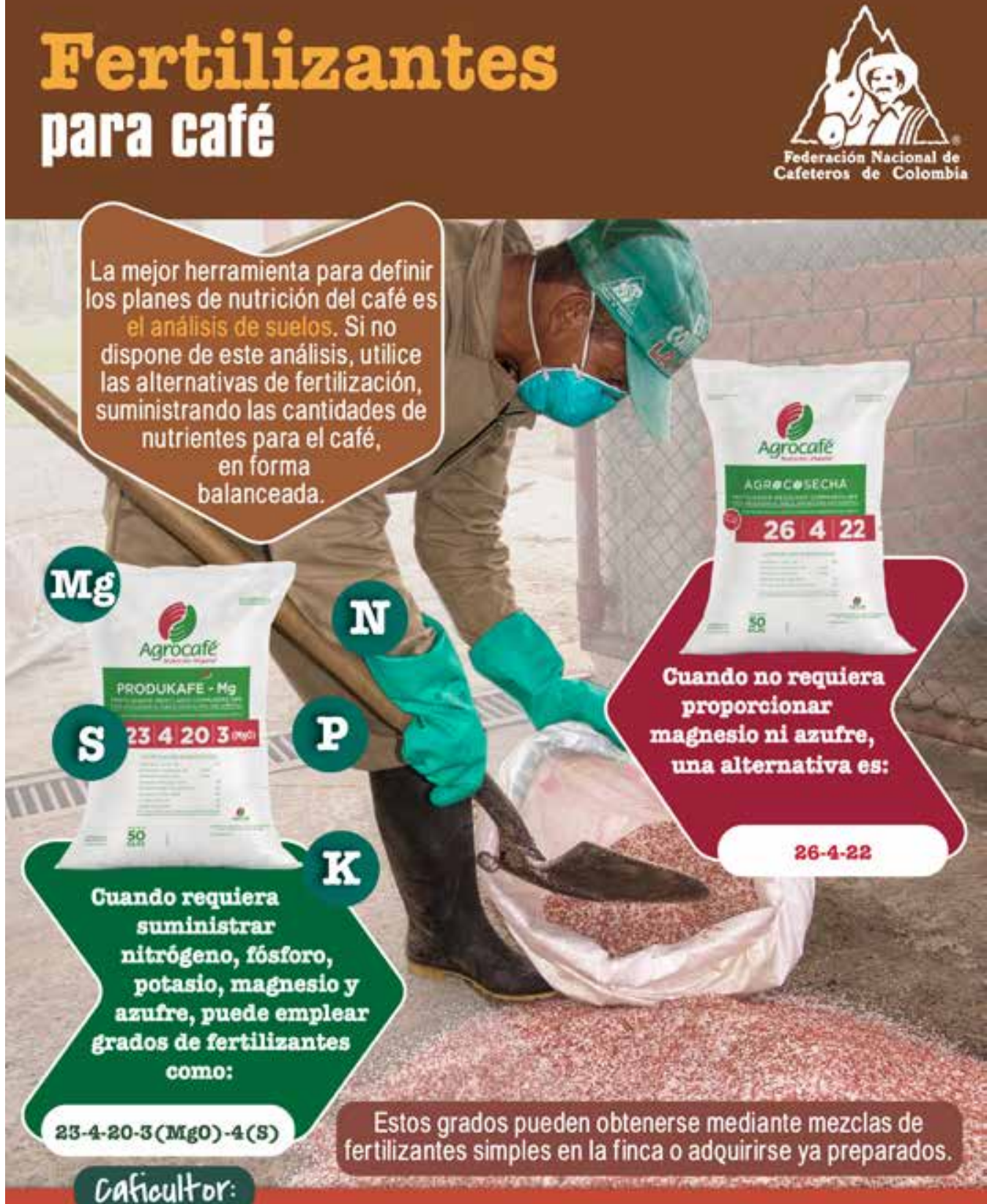

Mejore la productividad y la rentabilidad de sus cafetales aplicando

los nutrientes requeridos en forma balanceada.

consulte con su Extensionista

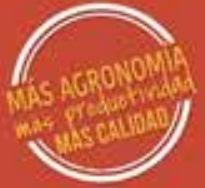

